\title{
Effect of AIDS-defining events at initiation of antiretroviral therapy on long-term mortality of HIV/AIDS patients in Southwestern China: a retrospective cohort study
}

Yunxuan Huang ${ }^{1 \dagger}$, Oulu Zhou ${ }^{2,3 \dagger}$, Zhigang Zheng ${ }^{3}$, Yuexiang Xu' ${ }^{1}$, Yi Shao $^{4}$, Chunwei Qin ${ }^{1}$, Fengxiang Qin ${ }^{3}$, Jingzhen Lai ${ }^{3}$, Huifang Liu ${ }^{3}$, Rongfeng Chen ${ }^{2,3}$, Li Ye $^{3}$, Hao Liang ${ }^{2,3}$, Xionglin Qin $^{{ }^{*}}$ and Junjun Jiang ${ }^{3^{*}}$

\begin{abstract}
Objective: To evaluate the impact of AIDS-defining events (ADE) on long-term mortality of HIV positive individuals on antiretroviral therapy (ART), a retrospective HIV/AIDS treatment cohort study performed in Southwestern China.

Methods: The retrospective cohort was conducted among 6757 HIV/AIDS patients on ART (2NRTIs + 1NNRTI, 2NRTIs + 1PI and Single or two drugs) recruited in Guigang city, Guangxi, China, from January 2004 to December 2018. Participants were divided into ADE and non-ADE groups, and were followed-up every six months to observe treatment outcomes. Comparison of mortality between groups was performed using the log-rank test and KaplanMeier analysis. Cox proportional hazard regression was used to explore the risk factors of mortality. 1:1 propensity score matching (PSM) was used to balance confounding factors and adjust the mortality risk.

Results: Of 6757 participants with 29,096.06 person-years of follow-up, 16.86\% (1139/6757) belonged to ADE group while the others (83.14\%) belonged to the non-ADE group. The most common cause of death by ADE was disseminated mycosis (31.65\%), followed by recurrent severe bacterial pneumonia (28.48\%), herpes zoster (17.72\%), and extra-pulmonary tuberculosis (8.86\%). The mortality of the ADE group was significantly higher than that of the non-ADE group [3.45/100 person-years ( $95 \% \mathrm{Cl} 2.92-3.97)$ vs. 2.34/100 person-years ( $95 \% \mathrm{Cl}$ 2.15-2.52), $P<0.001]$. The death risk of the ADE group was also higher than that of the non- ADE group [adjusted hazard ratio $(a H R)=1.291$, $95 \% \mathrm{Cl} 1.061-1.571, P=0.011$, which was confirmed by PSM analysis ( $\mathrm{AHR}=1.581,95 \% \mathrm{Cl} 1.192-2.099, P=0.002)$. Cox analysis indicated that $\mathrm{ADE}$, older age, male gender, previous non-use of cotrimoxazole, advanced WHO clinical stage, and low baseline $\mathrm{CD}^{+}$cell count were the risk factors for death.
\end{abstract}

Conclusions: Even on ART, the mortality risk of HIV positive individuals with ADE was higher than those without ADE. Active testing, earlier diagnosis, and timely therapy with ART may reduce the death risk of ADE.

Keywords: HIV, AIDS, Antiretroviral therapy, AIDS-defining events, Mortality

*Correspondence: ggqx12010@163.com; jiangjunjun@gxmu.edu.cn

†Yunxuan Huang and Oulu Zhou contributed equally to this work

1 Guigang Center for Disease Control and Prevention, Guigang 537100, Guangxi, China

${ }^{3}$ Guangxi Key Laboratory of AIDS Prevention and Treatment, Guangxi Medical University, Nanning 530021, Guangxi, China

Full list of author information is available at the end of the article

\section{Introduction}

Since the first case of the human immunodeficiency virus (HIV) infection was reported in 1981, 36.9 million people have been infected with HIV; the worldwide mortality rate of HIV/AIDS patients was $23.8 \%$ in 2017 [1]. As of August 31, 2018, 841,478 living HIV/ AIDS patients and 259,200 deaths had been registered

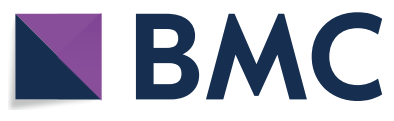

(c) The Author(s) 2020. This article is licensed under a Creative Commons Attribution 4.0 International License, which permits use, sharing, adaptation, distribution and reproduction in any medium or format, as long as you give appropriate credit to the original author(s) and the source, provide a link to the Creative Commons licence, and indicate if changes were made. The images or other third party material in this article are included in the article's Creative Commons licence, unless indicated otherwise in a credit line to the material. If material is not included in the article's Creative Commons licence and your intended use is not permitted by statutory regulation or exceeds the permitted use, you will need to obtain permission directly from the copyright holder. To view a copy of this licence, visit http://creativeco mmons.org/licenses/by/4.0/. The Creative Commons Public Domain Dedication waiver (http://creativecommons.org/publicdomain/ zero/1.0/) applies to the data made available in this article, unless otherwise stated in a credit line to the data. 
in China, with mortality rate of $23.55 \%$ [2, 3]. Guangxi, a province in Southwestern China, has the second highest number of reported HIV cases in the country, with 703,000 survivals and 40,500 deaths by 2017 . The mortality rate $(34.3 \%)$ was also higher than the national average mortality rate $(23.8 \%)$ during the same period [4]. In China, the National Free Antiretroviral Treatment Program (NFATP) began in 2002 and was scaled up in 2003. The "Treat for All" policy was implemented in 2016, and HIV positive individuals would be treated after diagnosis of HIV regardless of their $\mathrm{CD}^{+}$cell count [5-7]. However, research showed that $45.1 \%$ patients were in the advanced stages of AIDS when they were diagnosed [8], which might be the main reason for the high mortality rate in HIV positive individuals, even when they are on ART.

ART can significantly improve the prognosis of HIV infected people, and reduce the spread of HIV, which is more conducive to improving the prognosis and quality of life of patients [9]. At present, anti HIV drugs can be divided into six categories: nucleoside reverse transcriptase inhibitors (NRTIs), nonnucleoside reverse transcriptase inhibitors (NNRTIs), protease inhibitors (PIs), integrase inhibitors (INIs), fusion inhibitors and entry inhibitors. Then, the most widely used drugs are the first three categories in China. NRTIs mainly contains zidovudine (AZT), stavudine (D4T), lamivudine (3TC), tenofovir (TDF) and abacavir (ABC) et al.; NNRTIs mainly contains nevirapine (NVP), delavirdine, efavirenz (EFV) and etravirine et al.; and PIs mainly contains lopinavir (LPV), saquinavir, ritonavir and indinavir. In this study, the patients mainly used three kinds of antiviral treatment schemes: 2NRTIs + 1NNRTI, 2 NRTIs + 1PI and single or the combination of two drugs.

By 2017, 542,000 people living with HIV/AIDS (PLHIV) had received ART in China [2]. Research showed that ART also can effectively reduce mortality, delay the progression of the disease, prolong the development of non-AIDS-defining events (non-ADE) to ADE, reduce complications, and prolong lifespan [10]. However, ART-treated patients still face a higher mortality risk and lower quality of life than the general population [11-14]. Many studies have shown that a low $\mathrm{CD} 4^{+}$cell count, older age, male gender, clinical stage III/IV disease, low body mass index (BMI), and signs/symptoms of AIDS are independent factors related to death among patients on ART [4, 15-19], indicating that patients with ADE may have higher mortality. A study in Italy suggested that patients with ADE should be treated within 30 days after ADE diagnosis. However, only $43 \%$ of ADE patients in Italy received treatment [20]. A recent study also found that the presence of AIDS-defining disease at
HIV diagnosis was one of the factors related to high mortality [21].

So far, a number of studies have assessed in the relationship between ART and ADE, focusing on the relationships between ART [22-24], quality of life [25], cytomegalovirus infection [26], and the effect of the timing of ART on survival [27]. However, most studies in the field have explored the impact of ART on ADE. A retrospective study showed that $57 \%$ of patients with advanced HIV disease had opportunistic infections, and the majority were diagnosed when they had developed ADE [28]. Late diagnosis and delayed treatment of HIV infection contribute to the development of opportunistic infections, such as pneumocystis pneumonia, Talaromyces marneffei infection, etc. In Guangxi, a recent retrospective study revealed that $70.2 \%$ of newly diagnosed HIV cases from 2012 to 2016 had a late presentation, and $45.1 \%$ had advanced HIV disease [29]. Most patients with late presentation, advanced HIV disease, or ADE have relatively low $\mathrm{CD} 4^{+}$cell count or develop AIDS symptoms.

Comprehensively, we speculate that the high mortality rate of HIV/AIDS patients in Guangxi, China may be due to the high proportion of ADE in the ART population. Therefore, in this study, we aimed to evaluate the effect of ADE on the mortality rate of HIV/AIDS patients who were on ART, providing a basic understanding of the relationship between $A R T$ and $A D E$ from a perspective different from those of previous studies.

\section{Methods}

\section{Study site and population}

The HIV/AIDS treatment cohort in Guigang city, Guangxi, China was constructed from the treatment system starting in 2004. It was regarded as one of the longest observational treatment cohorts in Guangxi, since the treatment system was initiated simultaneously with the NFATP in China. We retrospectively extracted demographic information and data for ART-received patients who registered in the system between January 2004 and December 2018. The inclusion criteria for participants were as follows: (1) HIV-positive; (2) age at least 18 years; (3) received ART for the first time; (4) the disease category was recorded within 3 months of initiating antiviral treatment.

\section{Study design}

A retrospective cohort study was conducted among HIV/AIDS patients from NFATP at Guigang Center for Disease Control and Prevention, HIV/AIDS individuals who receiving ART from January 2004 to December 2018 were recruited for analysis. We mainly collected the demographic information of patients, data at the 
initiation of ART, as well as outcome of follow-up. Demographic information including age, gender, marital status, route of HIV infection; data at the initiation of ART including WHO clinical stage, previous use of cotrimoxazole, initial antiretroviral regimen, baseline $\mathrm{CD} 4^{+}$cell count, ADE (if valid), and as well as other clinical data. All the collected information was used to the subsequent analyses.

\section{Definitions}

AIDS-defining events: at least one of the diseases listed by the U.S. Centers for Disease Control (CDC) [30] or mentioned elsewhere. ART, a treatment regimen consisting of one or more of the following three drugs, including NRTIs, PIs and NNRTIs.

Endpoint: Death was validated as an endpoint, and censoring occurrence included lost to follow-up, transfer to another hospital, or cessation of ART.

\section{Statistical analysis}

Chi square test was used to compare demographic characteristics and mortality rates between the ADE group and the non-ADE group. Kaplan-Meier analysis was used to calculate the accumulated mortality. We used the stepwise selection method to choose the variables to enter into the multi-variable analysis model, and the cox model was used to calculate mortality risk. Then, 1:1 propensity score matching (PSM) was used to select individuals to eliminate the effects of the characteristics that were statistically different between the ADE and the nonADE groups. PSM used a calliper starting with 0.02 , and all statistical variables matched with 0.0001 callipers at the end. The analyses and mapping were performed using GraphPad Prism version 5.0 (GraphPad Software, San Diego, California, USA), Origin 2018, or Statistical Package for the Social Sciences (SPSS) version 22.0 (SPSS Inc. Chicago, USA). The significance level was set at 0.05 . All hypothesis tests were two-sided.

\section{Ethical considerations}

All records were extracted from the Internet-based NFATP system. The study was approved by the Human Research Ethics Committee of Guangxi Medical University (Ethical Review No. 2019-SB-102). Every participant in this study voluntarily signed the written informed consent. We guarantee that ID number, name, address will be replaced by digital codes in the analysis dataset. In addition, the access of the data used for analysis has been limited inside the task forces and will not reveal to others. Individuals involved in this study maybe at risk of the release of their HIV status, revealing of their private information, and facing social stigma as well. However, participants will benefit from the ART program which can improve their prognosis, help to enjoy their normal life. The public health community can also benefit from this study by understanding the role of ART has played in the prevention of $\mathrm{ADE}$.

\section{Results}

\section{Baseline characteristics}

The study included 7299 HIV/AIDS patients who initiated ART between January 2004 and December 2018 from the NFATP. Of those, 542 patients were excluded, including 76 without baseline information, 293 who quit ART, 158 without follow-up records, and 15 transferred to other hospitals. Ultimately, we enrolled 6757 eligible patients with 29,096.6 person-years of followup (Fig. 1). Among eligible patients, 1139 (16.86\%) were with ADE (ADE group) and 5618 (83.14\%) were without ADE (non-ADE group). The demographic characteristics of HIV/AIDS patients at ART initiation in the non-ADE and ADE groups were shown in Table 1. Between the two groups there was significant difference $(P<0.05)$ found for age, gender, route of HIV infection, WHO clinical stage, previous use of cotrimoxazole, and baseline $\mathrm{CD}^{+}{ }^{+}$cell count (Table 1 ).

\section{The causes of death by ADE}

Of all 6757 patients, 731 patients died, and 21.61\% (158/731) died of ADE. Among the causes by ADE, the most common cause of death was disseminated mycosis (31.65\%), followed by recurrent severe bacterial pneumonia (28.48\%), herpes zoster $(17.72 \%)$, extrapulmonary tuberculosis $(8.86 \%)$, and candidiasis of the oesophagus (5.70\%) (Table 2).

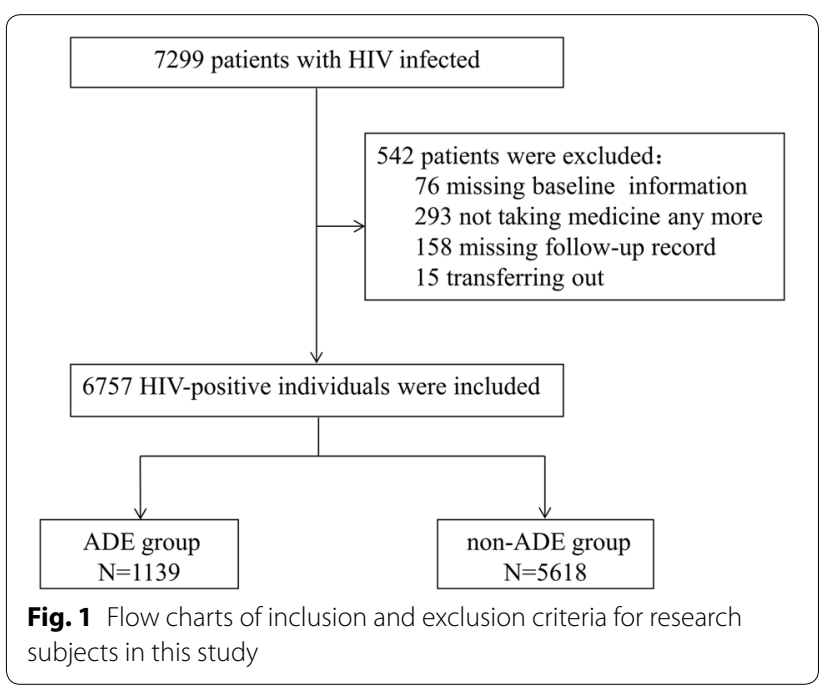


Table 1 Demographic characteristics of HIV/AIDS patients at ART initiation

\begin{tabular}{|c|c|c|c|c|c|}
\hline Demographic characteristics & $\begin{array}{l}\text { Total } \\
\mathrm{n}(\%)\end{array}$ & $\begin{array}{l}\text { ADE group } \\
n(\%)\end{array}$ & $\begin{array}{l}\text { Non-ADE group } \\
\mathrm{n}(\%)\end{array}$ & $x^{2}$ & $P$ \\
\hline Total & 6757 & 1139 & 5618 & & \\
\hline Age & & & & 39.41 & $<0.001$ \\
\hline$\leq 40$ & $2108(31.2)$ & $279(24.50)$ & $1829(32.56)$ & & \\
\hline $40<$ age $\leq 65$ & $3734(55.26)$ & $724(63.56)$ & $3010(53.58)$ & & \\
\hline$>65$ & $915(13.54)$ & $136(11.94)$ & $779(13.87)$ & & \\
\hline Gender & & & & 48.23 & $<0.001$ \\
\hline Male & $4619(68.36)$ & $878(77.09)$ & $3741(66.59)$ & & \\
\hline Female & $2138(31.64)$ & $261(22.91)$ & $1877(33.41)$ & & \\
\hline Marital status & & & & 1.766 & 0.414 \\
\hline Unmarried & $715(10.58)$ & $109(9.57)$ & $606(10.79)$ & & \\
\hline Married or living with a partner & $5026(74.38)$ & $851(74.71)$ & $4175(74.31)$ & & \\
\hline Divorced or widowed or other & $1016(15.04)$ & $179(15.72)$ & $837(14.9)$ & & \\
\hline Route of HIV infection & & & & 11.094 & 0.004 \\
\hline Blood or plasma transfusion & $352(5.21)$ & $45(3.95)$ & $307(5.46)$ & & \\
\hline Sexual transmission & $6104(90.34)$ & 1059 (92.98) & $5045(89.80)$ & & \\
\hline Other or unknown & $301(4.45)$ & $35(3.07)$ & $266(4.73)$ & & \\
\hline WHO clinical stage & & & & 1507.914 & $<0.001$ \\
\hline । & $2518(37.27)$ & $74(6.50)$ & $2444(43.50)$ & & \\
\hline$\|$ & $1138(16.84)$ & $125(10.97)$ & $1013(18.03)$ & & \\
\hline III & $1867(27.63)$ & $290(25.46)$ & $1577(28.07)$ & & \\
\hline IV & $1234(18.26$ & $650(57.07)$ & $584(10.40)$ & & \\
\hline Previous use of the cotrimoxazole & & & & 580.705 & $<0.001$ \\
\hline Yes & $1879(27.81)$ & $649(56.98)$ & $1230(21.89)$ & & \\
\hline No & $4878(72.19)$ & $490(43.02)$ & $4388(87.11)$ & & \\
\hline Initial antiretroviral regimen & & & & 0.61 & 0.737 \\
\hline $2 \mathrm{NRTIS}+1 \mathrm{NNRTI}$ & $5943(87.95)$ & $1002(87.97)$ & $4941(87.95)$ & & \\
\hline $2 N R T I s+1 P I$ & $517(7.65)$ & $83(7.29)$ & $434(7.73)$ & & \\
\hline Single or two drugs & $297(4.4)$ & $54(4.74)$ & $243(4.33)$ & & \\
\hline Baseline $\mathrm{CD} 4^{+}$cell count (cells/ $\mu \mathrm{L}$ ) & & & & 721.107 & $<0.001$ \\
\hline $\mathrm{CD} 4<50$ & $1900(28.12)$ & $675(59.26)$ & $1225(21.80)$ & & \\
\hline $50 \leq \mathrm{CD} 4<100$ & $796(11.78)$ & $137(12.03)$ & $659(11.73)$ & & \\
\hline $100 \leq C D 4<200$ & $1430(21.16)$ & $169(14.84)$ & $1261(22.45)$ & & \\
\hline $200 \leq C D 4<350$ & $1796(26.57)$ & $119(10.45)$ & $1677(29.85)$ & & \\
\hline$C D 4 \geq 350$ & $835(12.36)$ & $39(3.42)$ & $796(14.17)$ & & \\
\hline Duration of follow-up (years) ${ }^{a}$ & $4.00(1.92-6.50)$ & $3.58(1.75-6.00)$ & $4.17(2.00-6.58)$ & 3.64 & $<0.001$ \\
\hline
\end{tabular}

NRTI nucleoside reverse transcriptase inhibitor, NNRTI non-nucleoside reverse transcriptase inhibitor means, PI protease inhibitor

a Data are presented as medium, interquartile range (IQR), and T tests were used to compare the characteristics between the two groups

\section{ADE group had higher mortality}

A total of 731 out of $6757(10.81 \%)$ patients died during the 14-year period of follow-up, which contributed to a mortality rate of $2.51 / 100$ person-years (95\% CI 2.33-2.69); The mortality rates of the ADE group and the non-ADE group were $3.45 / 100$ person-years $(95 \%$ CI 2.92-3.97) and 2.34/100 person-years (95\% CI 2.15$2.52)$, respectively; the mortality rate of the $\mathrm{ADE}$ group was significantly higher than that of the non-ADE group (Table 3). In addition, Fig. 2 showed that the ADE group had a higher cumulative mortality rate than the non-ADE group when ART lasted for 5 years or longer (log-rank: $P<0.0001$ ) (Table 3).

\section{Factors related to mortality among HIV/AIDS patients on ART}

The cox model was used to identify factors related to death. Univariate analysis showed that the patients with ADE had a higher mortality rate than those patients without ADE, with a hazard ratio (HR) of 1.618 (95\% CI 
Table 2 The causes of death by ADE

\begin{tabular}{lcl}
\hline Death causes by ADE & Death number & $\begin{array}{l}\text { Percentage } \\
\text { of deaths (\%) }\end{array}$ \\
\hline Disseminated mycosis & 50 & 31.65 \\
Recurrent severe bacterial pneumonia & 45 & 28.48 \\
Herpes zoster & 28 & 17.72 \\
Extrapulmonary tuberculosis & 14 & 8.86 \\
Candidiasis of the esophagus & 9 & 5.70 \\
Pneumocystis pneumonia & 4 & 2.53 \\
Talaromyces marneffei infection & 3 & 1.90 \\
Disseminated non-tuberculous myco- & 2 & 1.27 \\
bacterium infection & & 1.27 \\
Cryptococcal infection of the lung & 2 & 0.63 \\
Chronic herpes simplex virus infection & 1 & 100 \\
Total death number & 158 & \\
\hline
\end{tabular}

1.356-1.931, $P<0.001)$. Multivariate analysis showed that the ADE group had a higher death risk than the non-ADE group, with an adjusted hazard ratio (aHR) of 1.291 (95\% CI 1.061-1.571, $P=0.011$ ). Cox analysis indicated that ADE, older age, male gender, previous non-use of cotrimoxazole, advanced WHO clinical stage, and low baseline $\mathrm{CD} 4^{+}$cell count were the risk factors for death (Table 4).

\section{Propensity score matching (PSM) analysis}

As Table 1 has shown, demographic characteristic variables including age, gender, route of HIV infection, WHO clinical stage, previous use of cotrimoxazole, and baseline $\mathrm{CD}^{+}{ }^{+}$cell counts were statistically different between the two groups. PSM analysis was used to match those characteristic variables between the two groups. Totally, 1720 patients (860 ADE and 860 non-ADE patients) were included. Chi squared test showed the differences in the above variables were not significant between the two groups after matching (Additional file 1: Table S1). The adjusted cox analysis showed that the ADE group still had a higher mortality rate than the non- $\mathrm{ADE}$ group $(\mathrm{HR}=1.325,95 \% \mathrm{CI}$ $1.016-1.728, P=0.038 ;$ aHR $=1.581,95 \%$ CI $1.192-$ 2.099, $P=0.002)$ (Table 5).

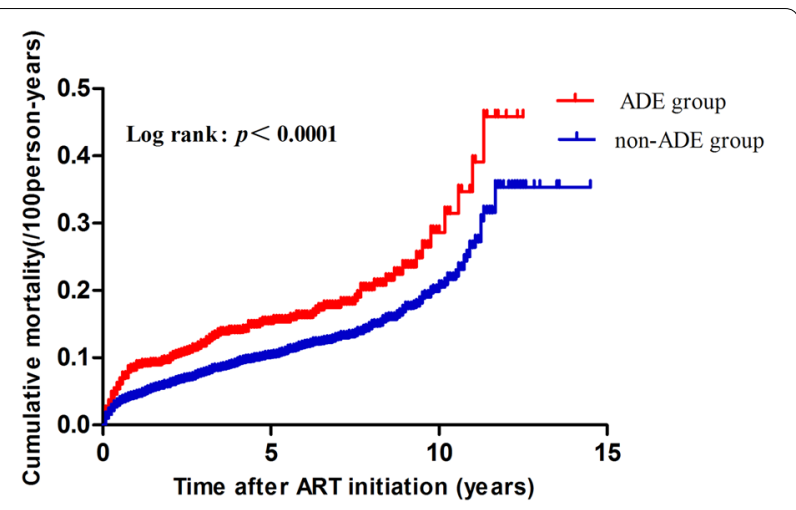

Fig. 2 Kaplan-Meier analysis of cumulative mortality of HIV/AIDS patients, grouped by ADE (The log-rank test was used for statistical)

\section{Discussion}

In this study, the prevalence of ADE in HIV/AIDS patients at ART initiation was $16.86 \%$, which was roughly consistent with the data of previous studies in other countries or regions; for example, a report from France showed that $16 \%$ of patients with newly diagnosed HIV were ADE [31]. Our study also showed that even when individuals were on ART, the mortality of patients with ADE was significantly higher than that of those without ADE, which was consistent with some previous studies: a large multi-centre cohort study showed that non-AIDS mortality was twice as high among patients with an ADE compared to without an ADE [32], and this multiple is a little higher than that of this study; a research showed that HIV controllers experience non-ADE, albeit at lower rates than patients who do not spontaneously control the virus [33]. While in this study, disseminated mycosis, recurrent severe bacterial pneumonia, herpes zoster, extra-pulmonary tuberculosis, and candidiasis of the oesophagus were the top causes of death by ADE.

Previous studies have shown that patients with a late diagnosis of HIV infection had a higher risk of mortality than those with an early HIV diagnosis [34], and universal ART among late presentation patients reduced mortality by just $10 \%$ [35]. Late presentation is defined well as, a patient diagnosed with the first $\mathrm{CD} 4^{+}$ cell count $<350 / \mu \mathrm{L}$, or a patient with AIDS-defining

Table 3 Comparison of mortality rate of HIV/AIDS patients between ADE and non-ADE group

\begin{tabular}{|c|c|c|c|c|c|c|c|}
\hline Group & Total (n) & $\begin{array}{l}\text { Deaths } \\
\text { n (\%) }\end{array}$ & $x^{2}$ & $P^{*}$ & Person-years & $\begin{array}{l}\text { Deaths/100 person- } \\
\text { years }(95 \% \mathrm{Cl})\end{array}$ & $P^{* *}$ \\
\hline ADE & 1139 & 158 (13.87) & 13.238 & $<0.001$ & 4586.17 & $3.45(2.92-3.97)$ & $<0.0001$ \\
\hline Non-ADE & 5618 & $573(10.20)$ & & & $24,510.42$ & $2.34(2.15-2.52)$ & \\
\hline Total & 6757 & 731 (10.82) & & & $29,096.6$ & $2.51(2.33-2.69)$ & \\
\hline
\end{tabular}

$P^{*}$ by Chi squared test; $P^{* *}$ by log-rank test 
Table 4 Cox analysis of risk factors for the death of HIV/AIDS patients on ART

\begin{tabular}{|c|c|c|c|c|c|}
\hline Variable & $n$ & Univariate analysis & $P$ & Multivariate analysis & $P$ \\
\hline \multicolumn{6}{|l|}{$\mathrm{ADE}$} \\
\hline No & 5618 & 1.00 & & 1.00 & \\
\hline Yes & 1139 & $1.618(1.356-1.931)$ & $<0.001$ & $1.291(1.061-1.571)$ & 0.011 \\
\hline Age & & & $<0.001$ & & $<0.001$ \\
\hline$\leq 40$ & 1210 & 1.00 & & 1.00 & \\
\hline $40<$ age $\leq 65$ & 3734 & $2(1.664-2.404)$ & $<0.001$ & $2.068(1.699-2.518)$ & $<0.001$ \\
\hline$>65$ & 915 & $3.927(3.191-4.831)$ & $<0.001$ & $3.653(2.896-4.607)$ & $<0.001$ \\
\hline \multicolumn{6}{|l|}{ Gender } \\
\hline Male & 4619 & 1.00 & & 1.00 & \\
\hline Female & 2138 & $0.475(0.394-0.574)$ & $<0.001$ & $0.563(0.463-0.686)$ & $<0.001$ \\
\hline Marital status & & & 0.027 & & 0.069 \\
\hline Unmarried & 715 & 1.00 & & 1.00 & \\
\hline Married or living with a partner & 5026 & $1.171(0.893-1.536)$ & 0.253 & $0.737(0.551-0.985)$ & 0.039 \\
\hline Divorced or widowed or other & 1016 & $1.462(1.071-1.994)$ & 0.017 & $0.845(0.601-1.187)$ & 0.331 \\
\hline Route of HIV infection & & & 0.372 & & \\
\hline Blood or plasma transfusion & 352 & 1.00 & & & \\
\hline Sexually transmitted & 6104 & $1.205(0.926-1.568)$ & 0.166 & & \\
\hline Other or unknown & 301 & $1.139(0.757-1.714)$ & 0.533 & & \\
\hline WHO clinical stage & & & $<0.001$ & & $<0.001$ \\
\hline । & 2510 & 1.00 & & 1.00 & \\
\hline$\|$ & 1132 & $0.954(0.733-1.242)$ & 0.727 & $0.863(0.7061 .055)$ & 0.150 \\
\hline III & 1863 & $1.057(0.847-1.319)$ & 0.625 & $1.095(0.838-1.430)$ & 0.506 \\
\hline IV & 1218 & $1.624(1.281-2.058)$ & $<0.001$ & $1.454(1.092-1.935)$ & 0.01 \\
\hline \multicolumn{6}{|l|}{ Previous use of the cotrimoxazole } \\
\hline Yes & 1879 & 1.00 & & 1.00 & \\
\hline No & 4878 & $0.406(0.34-0.486)$ & $<0.001$ & $0.4880 .403-0.592$ & $<0.001$ \\
\hline Initial antiretroviral regimen & & & $<0.001$ & & $<0.001$ \\
\hline $2 N R T I s+1 N N R T I$ & 5943 & 1.00 & & 1.00 & \\
\hline $2 N R T I s+1 P I$ & 517 & $6.212(4.762-8.103)$ & $<0.001$ & $4.721(3.577-6.23)$ & $<0.001$ \\
\hline Single or two drugs & 297 & $1.122(0.844-1.49)$ & 0.428 & $1.163(0.87-1.555)$ & 0.307 \\
\hline Baseline $\mathrm{CD}^{+}{ }^{+}$cell count (cells/ $\mu \mathrm{L}$ ) & & & $<0.001$ & & $<0.001$ \\
\hline$C D 4 \geq 350$ & 835 & 1.00 & & 1.00 & \\
\hline $200 \leq \mathrm{CD} 4<350$ & 1796 & $0.742(0.442-1.247)$ & 0.260 & $0.794(0.468-1.345)$ & 0.39 \\
\hline $100 \leq \mathrm{CD} 4<200$ & 1430 & $1.263(0.762-2.095)$ & 0.365 & $1.244(0.739-2.094)$ & 0.41 \\
\hline $50 \leq C D 4<100$ & 796 & $1.484(0.886-2.487)$ & 0.134 & $1.56(0.911-2.669)$ & 0.11 \\
\hline $\mathrm{CD} 4<50$ & 1900 & $1.898(1.162-3.103)$ & 0.011 & $1.846(1.095-3.114)$ & 0.02 \\
\hline
\end{tabular}

Table 5 Crude and adjusted risk ratios for predictors of mortality in ADE and non-ADE groups

\begin{tabular}{|c|c|c|c|c|c|c|c|}
\hline$\overline{A D E}$ & $\begin{array}{l}\text { Total patients, } \\
\mathrm{n}\end{array}$ & Deaths n (\%) & $\begin{array}{l}\text { Deaths } / 100 \text { person- } \\
\text { years }(95 \% \mathrm{Cl})\end{array}$ & $\mathrm{HR}(95 \% \mathrm{Cl})$ & $P$ & aHR $(95 \% \mathrm{Cl})$ & $P$ \\
\hline No & 860 & $100(11.63)$ & $2.80(2.26-3.33)$ & 1.00 & - & 1.00 & - \\
\hline Yes & 860 & $124(14.42)$ & $3.41(2.83-4.00)$ & $1.325(1.016-1.728)$ & 0.038 & 1.581 (1.192-2.099) & 0.002 \\
\hline
\end{tabular}

aHR adjusted by age at ART, gender, marital status, route of HIV infection, WHO clinical stage before ART, Previous use of the cotrimoxazole, initial antiretroviral regimen, baseline $\mathrm{CD}^{+}{ }^{+}$cell count 
illness regardless of $\mathrm{CD}^{+}$cell count during diagnosis $[8,36,37]$. In this study, the median $\mathrm{CD} 4^{+}$cell count in the ADE group was 29.00 cells/ $\mu \mathrm{L}$ (IQR: $12.00-116.50$ ), and $96.05 \%$ of patients with ADE had late presentation, demonstrating that most of patients with ADE were in an advanced stage of HIV/AIDS. And studies showed that low $\mathrm{CD}^{+}$cell count (baseline $\mathrm{CD} 4$ count $\leq 50$ cells $/ \mu \mathrm{L}$ ) was related to treatment failure $[38,39]$, a lower $\mathrm{CD}_{4}^{+}$ cell count was always associated with a higher risk of a new AIDS events or death [40].

A delay in the diagnosis of patients with ADE postpones HIV care and the administration of ART, which further reduces the possibility of achieving viral suppression. In addition, even on ART, most of the patients with ADE at advanced HIV/AIDS stages may also have failed immunological recovery, thus increasing the risk of morbidity and mortality.

A number of studies have shown that early diagnosis and treatment at a higher $\mathrm{CD} 4^{+}$cell count without ADE could benefit patients in terms of preserving immune function and reducing the risk of mortality $[20,41,42]$. However, many HIV-infected people were unaware of their infection status. In the United States, $15 \%$ of HIV/ AIDS patients were unaware of their HIV infection status [43], and only $40 \%$ of the adult population had undergone HIV testing [44]. HIV screening, especially in HIV high risk populations including men who have sex with men (MSM), female sexual workers (FSW), and bisexuals may be valuable for earlier diagnosis [45]. Therefore, to reduce HIV transmission and improve the effect of ART, HIV infection needs to be diagnosed as early as possible. Our study found that patients aged from 40 to 65 years, following sexual transmission, with previous non-use of cotrimoxazole, and a low baseline $\mathrm{CD} 4^{+}$cell count tended to have a higher risk of death. Therefore, increasing active HIV testing coverage and frequency should be implemented in high-risk populations. Once HIV infection is confirmed, ART should be provided immediately, which is expected to reduce the incidence of ADE and thus reduce mortality.

The study had a large sample size and long-term investigation, so that the study has a certain representative of ART outcomes in Guangxi and Southwestern China. In addition, this data collection began in 2004, and the cohort was well followed-up through the whole NFATP period in China, which can fully evaluate the impact of ADE on mortality for patients on ART. Several limitations of our study should also be mentioned. Firstly, this study is a retrospective cohort study, and the subjects were from a city in Guangxi, which may lead to a loss of access bias and selection bias. However, the large sample size (HIV/AIDS patients may come from other places in Guangxi or the country) may reduce these biases to some extent. Secondly, many patients in this study had no viral load data at the initiation of ART, and we could not assess the impact of viral load on treatment outcomes. Thirdly, our analysis did not include surveys of patient compliance with medication.

In conclusion, in the era of ART, it is still common for patients with initial ART to have ADE. Even on ART, these patients have a higher risk of death than those without ADE. Currently there is no cure for HIV/AIDS, and we should further promote voluntary testing and improve people's awareness of early diagnosis to reduce late presentations, especially those with $\mathrm{ADE}$.

\section{Supplementary information}

Supplementary information accompanies this paper at https://doi. org/10.1186/s12981-020-00300-4.

Additional file 1: Table S1. After PSM, demographic characteristics of HIV/AIDS patients at initiation of ART.

\section{Acknowledgements}

We would like to express our gratitude to all participants involved in this study and the staff of Guigang Center for Disease Control for their support.

\section{Authors' contributions}

$Y H, Y X, C Q, X Q$ collected and provided the data. $J \mathrm{~L}, \mathrm{HL}, \mathrm{RC}$ extracted data and cleaned data. $X Q, J J, L Y, H L$ designed the study and provided the correlative Knowledge. OZ analyzed the data. YH, OZ, ZZ drafted of the manuscript. All authors read and approved the final manuscript.

\section{Funding}

This study was supported by the National Natural Science Foundation of China (NSFC, 81960602), Guangxi Science Fund for Distinguished Young Scholars (2018GXNSFFA281001), Guangxi Bagui Scholar (to Junjun Jiang), Thousands of Young and Middle-aged Key Teachers Training Program in Guangxi Colleges and Universities (to Junjun Jiang), Guangxi Medical University Training Program for Distinguished Young Scholars (to Junjun Jiang), Guangxi Key Research and Development Plan (GuikeAB18050022).

\section{Ethics approval and consent to participate}

The study was approved by the Human Research Ethics Committee of Guangxi Medical University (Ethical Review No. 2019-SB-102).

\section{Competing interests}

The authors declare that they have no financial conflicts of interest.

\section{Author details}

${ }^{1}$ Guigang Center for Disease Control and Prevention, Guigang 537100, Guangxi, China. ${ }^{2}$ Life Sciences Institute, Guangxi Medical University, Nanning 530021, Guangxi, China. ${ }^{3}$ Guangxi Key Laboratory of AIDS Prevention and Treatment, Guangxi Medical University, Nanning 530021, Guangxi, China. ${ }^{4}$ Guigang Maternal and Child Health Hospital, Guigang 537100, Guangxi, China

Received: 1 April 2020 Accepted: 7 July 2020

Published online: 17 July 2020

\section{References}

1. Joint United Nations Programme on HIV/AIDS. UNAIDS data 2018. Geneva: United Nations Publishing; 2018. https://www.unaids.org/en/ resources/documents/2018/unaids-data-2018. 
2. NCAIDS, NCSTD, China, CDC. Update on the AIDS/STD epidemic in China in August, 2018; 24(10):965. Chinese Journal of AIDS \& STD.2018; 24(10):965. https://doi.org/10.13419/j.cnki.aids.2018.10.01.

3. Da W, Li X, Qiao S, Zhou Y, Shen Z. Antiretroviral therapy and mental health among people living with HIV/AIDS in China. Psychol Health Med. 2020;25:45-52. https://doi.org/10.1080/13548506.2019.1616101.

4. Jiang J, Qin X, Liu H, Meng S, Abdullah AS, Huang J, et al. An optimal BML range associated with a lower risk of mortality among HIV-infected adults initiating antiretroviral therapy in Guangxi, China. Sci Rep. 2019;9(1):7816.

5. Zhang F, Dou Z, Ma Y, Zhang Y, Zhao Y, Zhao D, et al. Effect of earlier initiation of antiretroviral treatment and increased treatment coverage on HIV-related mortality in China: a national observational cohort study. Lancet Infect Dis. 2011;11(7):516-24.

6. Zhang F, Haberer JE, Wang Y, Zhao Y, Ma Y, Zhao D, et al. The Chinese free antiretroviral treatment program: challenges and responses. AIDS (London, England). 2007;21(Suppl 8):S143-8.

7. Dou Z, Chen RY, Xu J, Ma Y, Jiao JH, Durako S, et al. Changing baseline characteristics among patients in the China National Free Antiretroviral Treatment Program, 2002-09. Int J Epidemiol. 2010;39(Suppl 2):ii56-64. https://doi.org/10.1093/ije/dyq215.

8. Hu X, Liang B, Zhou C, Jiang J, Huang J, Ning C, et al. HIV late presentation and advanced HIV disease among patients with newly diagnosed HIV/ AIDS in Southwestern China: a large-scale cross-sectional study. AIDS Res Ther. 2019:16(1):6.

9. The INSIGHT START Study Group. Initiation of antiretroviral therapy in early asymptomatic HIV infection. N Engl J Med. 2015;373(9):795-807.

10. Sun GM, Gu KK, Han ZHY. Life expectancy of 917 cases with HIV/AIDS in Shanghai. Chin prev Med. 2019;20(01):32-6. https://doi.org/10.16506 /j.1009-6639.

11. Badje A, Moh R, Gabillard D, Guéhi C, Kabran M, Ntakpé JB, et al. Effect of isoniazid preventive therapy on risk of death in west African, HIV-infected adults with high CD4 cell counts: long-term follow-up of the Temprano ANRS 12136 trial. Lancet Global Health. 2017;5(11):e1080-9.

12. Mangal TD, Meireles MV, Pascom ARP, de Almeida Coelho R, Benzaken AS, et al. Determinants of survival of people living with HIV/AIDS on antiretroviral therapy in Brazil 2006-2015. BMC Infect Dis. 2019;19(1):206.

13. Shriharsha C, Rentala S. Quality of life among people living with HIV/ AIDS and its predictors: a cross-sectional study at ART center, Bagalkot, Karnataka. J Family Med Prim Care. 2019;8(3):1011-6.

14. Tao L, Liu M, Li S, Liu J, Wang N. Condom use in combination with ART can reduce HIV incidence and mortality of PLWHA among MSM: a study from Beijing, China. BMC Infect Dis. 2018;18(1):124

15. Xu YY, Zhu ZHP, Wu SS, Liu L, Guo L, Li X, et al. Survival of HIV/AIDS patients receiving highly antiretroviral therapy in Nanjing city, 2004-2016. Chin J Public Health. 2018;24(07):697-701. https://doi.org/10.11847/ zgggws1116546.

16. Sun XM, Ma FH, Zhao JW, Zhuoma L, He Y, Dazheng C, et al. Survival analysis of adult HIV/AIDS patients receiving antiviral treatment in Zhaojue. Chin J Dis Control Prev. 2018;22(12):1221-4. https://doi.org/10.16462 /j.cnki.zhjbkz.2018.12.005.

17. Chen J, Xu M, Zhao X, Huang CH, Lu HY. Analysis of the survival conditions of HIV/AIDS patients receiving antiretroviral therapy in Beijing in 2005-2015 and the related factors. Chin J Dis Control Prev. 2018;22(12):1225-8. https://doi.org/10.16462/j.cnki.zhjbkz.2018.12.006.

18. Sun Y, Zhao QX, Li CF, Yang X, Zhang X, Liu CL, et al. Analysis on 10 year survival of HIV/AIDS patients receiving antiretroviral therapy during 20032005 in Henan province. Chin J Epidemiol. 2018;39(7):966-70. https://doi. org/10.3760/cmaj.issn.0254-6450.2018.07.019.

19. Zhang $N$, Zhu XY, Wang GY, Tao XR, Wang N, Kang DM, et al. Survival status and influencing factors of HIV/AIDS on highly active anti-retrovial therapy in Shandong province. Chin J Epidemiol. 2019;40(1):74-8. https:// doi.org/10.3760/cma.j.jssn.0254-6450.2019.01.015.

20. Cingolani A, Cozzi-Lepri A, Ammassari A, Mussini C, Ursitti MA, Caramello $P$, et al. Timing of antiretroviral therapy initiation after a first AIDS-defining event: temporal changes in clinical attitudes in the ICONA cohort. PLoS ONE. 2014;9(2):e89861.

21. Liu WD, Tsai WC, Hsu WT, Shih MC, Chen MY, Sun HY, et al. Impact of initiation of combination antiretroviral therapy according to the WHO recommendations on the survival of HIV-positive patients in Taiwan. J Microbiol Immunol Infect. 2019. https://doi.org/10.1016/j.jmii.2019.03.008.
22. Traisathit P, Delory T, Ngo-Giang-Huong N, Somsamai R, Techakunakorn P, Theansavettrakul $S$, et al. Brief report: AIDS-defining events and deaths in HIV-infected children and adolescents on antiretrovirals: a 14-year study in Thailand. J Acquir Immune Defic Syndr. 2018;77(1):17-22. https://doi. org/10.1097/QAl.0000000000001571.

23. Judd A, Chappell E, Turkova A, LeCoeur S, Noguera-Julian A, Goetghebuer $\mathrm{T}$, et al. Long-term trends in mortality and AIDS-defining events after combination ART initiation among children and adolescents with perinatal HIV infection in 17 middle- and high-income countries in Europe and Thailand: a cohort study. PLoS ONE. 2018;15(1):1002491.

24. Sarfo FS, Sarfo MA, Norman B, Phillips R, Bedu-Addo G, Chadwick D. Risk of deaths, AIDS-defining and non-AIDS defining events among Ghanaians on long-term combination antiretroviral therapy. PLOS ONE. 2014;9(10):111400.

25. Anis AH, Nosyk B, Sun H, Guh DP, Bansback N, Li X, et al. Quality of life of patients with advanced HIV/AIDS: measuring the impact of both AIDSdefining events and non-AIDS serious adverse events. J Acquir Immune Defic Syndr. 2009;51(5):631-9. https://doi.org/10.1097/QAl.0b013e3181 a4food.

26. Lichtner M, Cicconi P, Vita S, Galli M, Lo Caputo S, Saracino A, et al. Cytomegalovirus coinfection is associated with an increased risk of severe non-AIDS-defining events in a large cohort of HIV-infected patients. J Infect Dis. 2015;211(2):178-86.

27. Miro JM, Manzardo C, Mussini C, Johnson M, ArminioMonforte A, Antinori A, et al. Survival outcomes and effect of early vs deferred cART among HIV-infected patients diagnosed at the time of an AIDS-defining event: a cohort analysis. PLoS ONE. 2011;6(10):e26009.

28. Smurzynski M, Wu K, Benson CA, Bosch RJ, Collier AC, Koletar SL. Relationship between CD4+ T-cell counts/HIV-1 RNA plasma viral load and AIDSdefining events among persons followed in the ACTG longitudinal linked randomized trials study. Acquir Immune Defic Syndr. 2010;55:117-27.

29. Tang Z, Pan SW, Ruan Y, Liu X, Su J, Zhu Q, et al. Effects of high CD4 cell counts on death and attrition among HIV patients receiving antiretroviral treatment: an observational cohort study. Sci Rep. 2017;7:3129.

30. Centers for Disease Control and Prevention (CDC). Revised surveillance case definition for HIV infection-United States, 2014. MMWR Recomm Rep. 2014;63(03):1-10.

31. Champenois K, Cousien A, Cuzin L, Le Vu S, Deuffic-Burban S, Lanoy E, et al. Missed opportunities for HIV testing in newly-HIV-diagnosed patients, a cross sectional study. BMC Infect Dis. 2013;13:200.

32. Pettit AC, Giganti MJ, Ingle SM, May MT, Shepherd BE, Gill MJ, et al. Increased non-AIDS mortality among persons with AIDS-defining events after antiretroviral therapy initiation. J Int AIDS Soc. 2018;21:1.

33. Dominguez-Molina B, Leon A, Rodriguez C, Benito JM, Lopez-Galindez C, Garcia F, et al. Analysis of non-AIDS-defining events in HIV controllers. Clin Infect Dis. 2016;62(10):1304-9.

34. Belay H, Alemseged F, Angesom T, Hintsa S, Abay M. Effect of late HIV diagnosis on HIV-related mortality among adults in general hospitals of Central Zone Tigray, northern Ethiopia: a retrospective cohort study. HIV AIDS. 2017;9:187-92.

35. Belaunzaran-Zamudio PF, Caro-Vega YN, Shepherd BE, Rebeiro PF, Crabtree-Ramírez BE, Cortes CP, et al. The population impact of late presentation with advanced HIV disease and delayed antiretroviral therapy in adults receiving HIV care in Latin America. Am J Epidemiol. 2019. https:// doi.org/10.1093/aje/kwz252.

36. Lo Y-C, Wu P-Y, Hsieh C-Y, Chen MY, Sheng WH, Hsieh SM, et al. Late diagnosis of human immunodeficiency virus infection in the era of highly active antiretroviral therapy: role of socio-behavioral factors and medical encounters. J Formos Med Assoc. 2011;110(5):306-15.

37. Smith RD, Delpech VC, Brown AE, Rice BD. HIV transmission and high rates of late diagnoses among adults aged 50 years and over. AIDS. 2010;24(13):2109-15.

38. Telele NF, Kalu AW, Marrone G, Marrone G, Gebre-Selassie S, Fekade D, et al. Baseline predictors of antiretroviral treatment failure and lost to follow up in a multicenter countrywide HIV-1 cohort study in Ethiopia. PLoS ONE. 2018;13(7):e0200505.

39. Bezabih YM, Beyene F, Bezabhe WM. Factors associated with first-line antiretroviral treatment failure in adult HIV-positive patients: a casecontrol study from Ethiopia. BMC Infect Dis. 2019;19(1):537.

40. Young J, Psichogiou M, Meyer L, Ayayi S, Grabar S, Raffi F, et al. CD4 cell count and the risk of AIDS or death in HIV-Infected adults on 
combination antiretroviral therapy with a suppressed viral load: a longitudinal cohort study from COHERE. PLOS Med. 2012;9(3):e1001194.

41. Fauci AS, Redfield RR, Sigounas G, Weahkee MD, Giroir BP. Ending the HIV epidemic: a plan for the United States. JAMA. 2019;321(9):844-5.

42. Lundgren JD, Babiker AG, Gordin F, Emery S, Grund B, et al. Initiation of antiretroviral therapy in early asymptomatic HIV infection. N Engl J Med. 2015;373(9):795-807.

43. Announcement: Monitoring Selected National HIV Prevention and Care Objectives. Morbidity Mortal Wkly Rep. 2017; 66(29):794.

44. Pitasi MA, Delaney KP, Brooks JT, DiNenno EA, Johnson SD, Prejean J. HIV Testing in 50 local jurisdictions accounting for the majority of new HIV diagnoses and seven states with disproportionate occurrence of HIV in rural areas, 2016-2017. Morbidity Mortal Wkly Rep. 2019;68(25):561-7.

45. DiNenno EA, Prejean J, Irwin K, Delaney KP, Bowles K, Martin T, et al. Recommendations for HIV screening of gay, bisexual, and other men who have sex with men, United States, 2017. Morbidity Mortal Wkly Rep. 2017;66(31):830-2.

\section{Publisher's Note}

Springer Nature remains neutral with regard to jurisdictional claims in published maps and institutional affiliations.
Ready to submit your research? Choose BMC and benefit from:

- fast, convenient online submission

- thorough peer review by experienced researchers in your field

- rapid publication on acceptance

- support for research data, including large and complex data types

- gold Open Access which fosters wider collaboration and increased citations

- maximum visibility for your research: over $100 \mathrm{M}$ website views per year

At BMC, research is always in progress.

Learn more biomedcentral.com/submissions 